\title{
XI
}

\section{Recent Studies on the}

\section{Ctenophora}

\author{
G. A. HORRIDGE
}

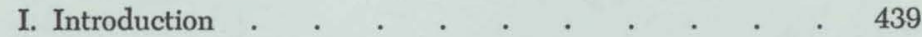

II. Systems of Coordination . . . . . . . . 441
A. The Apical Organ
441
B. Transmission of the Ciliary Wave along the Comb Rows
C. Fingers of Leucothea . . . . . . . . . 451
D. Swimming of Cestus . . . . . . . 456
E. The Feeding Response of Berö̈ . . . . . . 457
III. The Nervous System of Ctenophores . . . . . 458

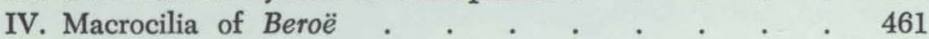

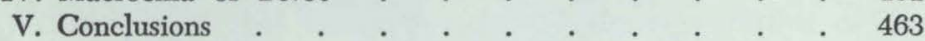
References . . . . . . . . . . . . 467

\section{INTRODUCTION}

The delightful, distinct, and interesting group of animals forming the clearly delineated phylum Ctenophora are similar in many features to Cnidaria, but they do not possess cnidae (nematocysts). They are at a similar tissue rather than organ level of organization in that their main body systems are distributed as thin layers over mesoglea as in Cnidaria. The ctenophores converge with medusae in specializations for a planktonic mode of life, such as voluminous mesoglea, trailing tentacles, and buoyancy mechanisms based on concentrations of ions, but they differ sharply from medusae in histology and especially in their fine structure. Whereas an ecologist might classify the ctenophores with Cnidaria, an electron microscopist would see major differences in all tissues. 

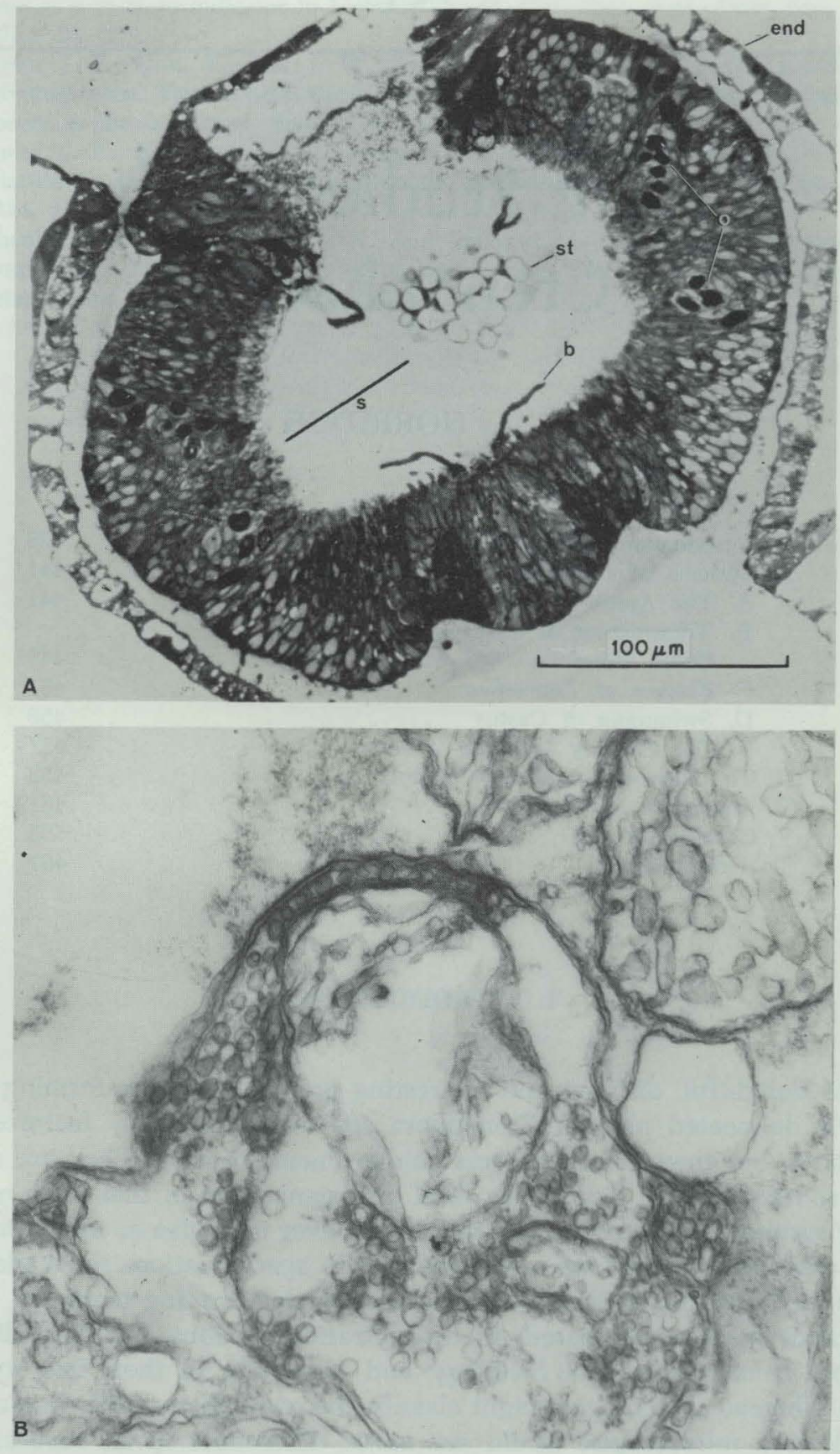
Over the past two decades the fine structure and the coordination between cells and parts of the body are the aspects of ctenophore biology that have become better known. These studies have led to general conclusions which make it worthwhile learning about ctenophores for the principles which they illustrate. The following account is essentially a bringing up to date of certain sections of the excellent general account of ctenophores by Hyman (1940). The new material, amplifying and correcting older accounts, concerns the sense organs, the systems conducting excitation throughout the animal, the control of movement or responses, and the fine structure as revealed by electron microscopy.

\section{SYSTEMS OF COORDINATION}

A number of functional systems, each of which is a combination of a sensory input, a conducting pathway, and an effector, can be conveniently distinguished in the analysis of ctenophore behavior. Each type of ctenophore, such as Beroë, Cestus, or Leucothea, has several of these systems but no one species has them all. The study of each system involves knowledge of its morphology and physiology and usually it is possible to outline the significance of the system in the life of the animal. None of these systems of coordination are as yet adequately understood, but they provide excellent examples of the primitive organization of behavior.

\section{A. The Apical Organ}

\section{MORPHOLOGY}

The apical organ is one of the few structures that resembles an organ in ctenophores. It consists of a pit, called a statocyst, of modified ciliated epithelium containing a calcareous statolith (Figs. 1A, 2, 3, and 4).

Fig. 1. (A) Transverse section through the apical organ of Pleurobrachia, showing grains of the statocyst (st) in the center and four groups of balancer cilia (b) which support the statocyst. Lodged within the thick epithelium of columnar cells are a few of the presumed photoreceptor organs $(0)$. The line $s$ shows the sagittal plane as defined by Hyman (1940). (B) A typical example of the synaptic structures which are found where nerve fibers meet ciliated cells and which are thought to be inhibitory. Within the area which is identified as a nerve terminal are numerous characteristic vesicles. A row of vesicles is trapped between the specialized region of the membrane and a poorly fixed mitochondrion. end, Endoderm. 


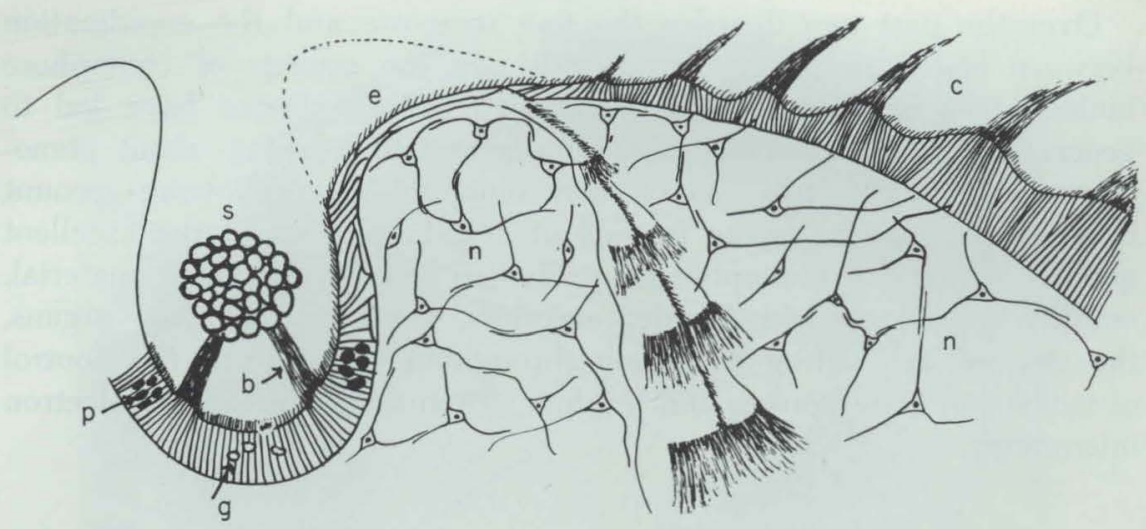

Fig. 2. The arrangement of the principal components in the apical organ/comb row system. b, Balancer cilia; c, comb plate; e, elongated cells of the ciliated groove; $\mathrm{g}$, grains of statolith being formed; $\mathrm{n}$, general epithelial nerve net; $\mathrm{p}$, presumed photoreceptor organelles; s, statolith within the statocyst.

Although it is clearly sensitive to mechanical disturbance and the direction of gravity, the apical organ contains no intrinsic neurons nor, surprisingly, any sensory neurons with axons. Therefore the apical organ is certainly not a ganglion, as has been suggested in earlier accounts
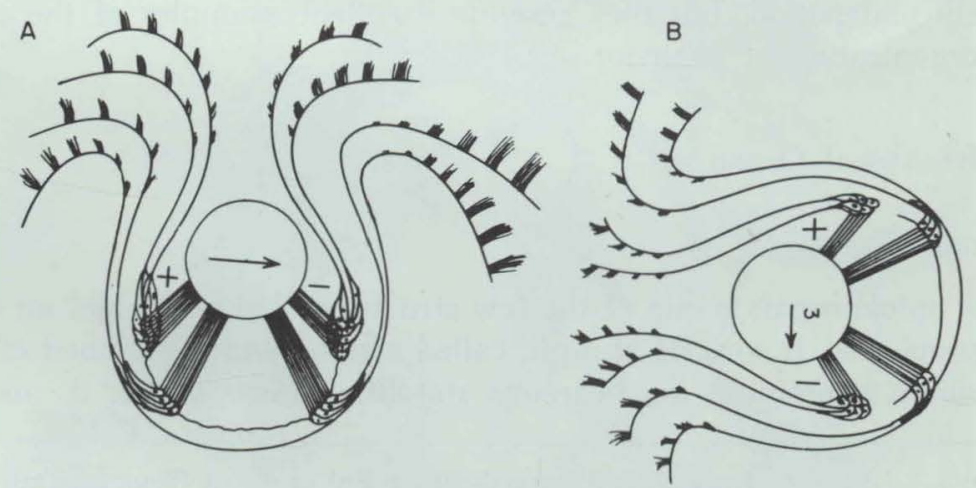

Fig. 3. The sensitivity of the balancer cilia in ctenophores. (A) With the apical organ pointing upwards, a deflection of the statolith to the right with a micromanipulator causes acceleration of the beat frequency on the left and deceleration on the right. (B) With the animal swimming along on its side the weight of the statolith now has the effect shown in A. This example would therefore tend to swim downward, as do all planktonic ctenophores when disturbed. 


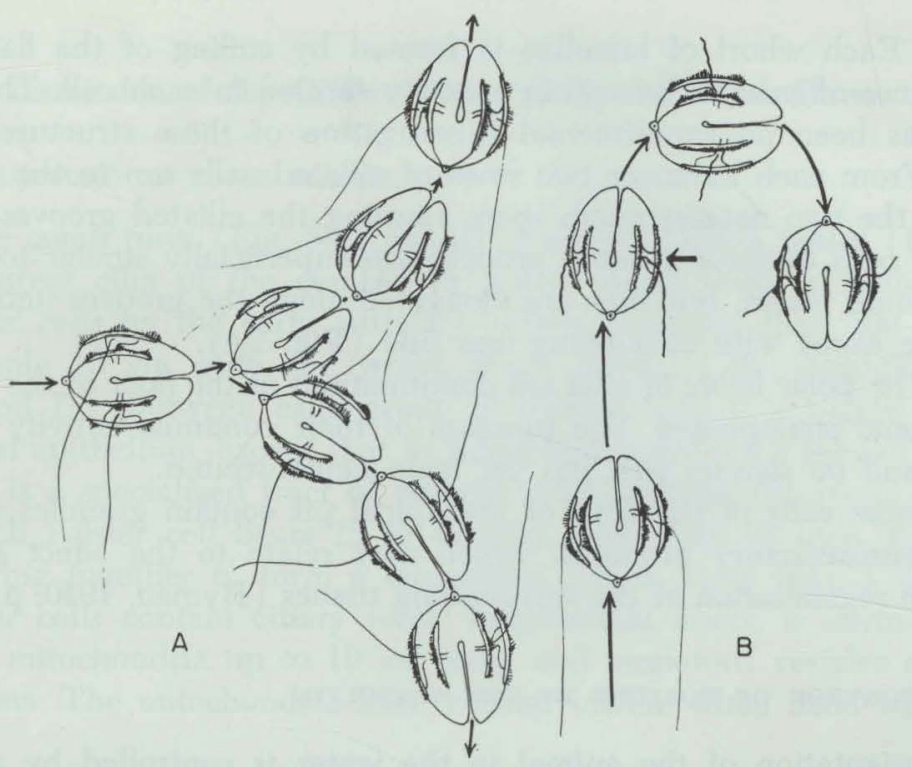

Fig. 4. The effect of the control by the statocyst in Pleurobrachia. (A) A horizontally swimming animal turns upward or downward by relative increase of the frequency of the ciliary waves on the lower or uppermost comb rows, respectively. (B) When an upwardly swimming animal is stimulated (indicated by the arrow) by underwater vibration or otherwise, there is a retraction of tentacles, temporary arrest of ciliary waves, and then a reversal of the direction of swimming.

(see Hyman, 1940). The following types of specialized ciliated epithelial cells have been recognized in the apical organ (Horridge, 1965c).

(a) Four balancers within the statocyst support the statolith. Each balancer consists of cilia, the tips of which are embedded among the statolith cells. The group of cilia arise from about 100 cells, each with many cilia. These cilia beat at a frequency controlled by the load upon them and thereby give rise to the reflex control of orientation.

(b) Cupula cells are arranged in a circle around the sides of the statocyst cavity, and their cilia form a transparent dome over it (Fig. 2). Cupula cilia adhere together and have never been seen to move. Although otherwise normal in the structure of the shaft, cupula cilia have a characteristic fan-shaped root which lies at right angles to their shaft.

(c) Presumed photoreceptors lie in four groups in the floor of the apical organ in some genera (Figs. 1A and 2). Known as colored spots to Chun (1880), they have proved to consist each of a group of cilia modified as an onionlike body of many concentric layers (Horridge, 
1964a). Each whorl of lamellae is formed by coiling of the flattened membranes of many cilia within a cavity formed in each cell. Thus far there has been no experimental investigation of these structures.

(d) From each balancer two rows of ciliated cells run to the beginning of the two nearest comb rows, forming the ciliated grooves (Fig. 2 ). The cells of these ciliated grooves are superficially similar to those of the comb plates, but they are elongated along the grooves until they resemble axons with cilia along one side (Fig. 2,e).

(e) The polar fields of cilia are continuations of the floor of the apical pit in some ctenophores. The function of their continual activity is not known and no sensory role has yet been demonstrated.

(f) Some cells of the floor of the apical pit contain granules resembling neurosecretory products, which may relate to the effect of this organ on regeneration of the surrounding tissues (Hyman, 1940, p. 692).

\section{THE CONTROL OF POSTURE BY THE STATOLITH}

The orientation of the animal in the water is controlled by a very simple mechanism (Horridge, 1965c, 1966). As the statolith bears its weight upon them, the balancer cilia change the rate of their beat. This response can be shown directly in Pleurobrachia by deflecting the statolith with a micromanipulator while observing the beats of the balancer cilia under a binocular microscope (Fig. 3).

Depending on whether the animal is tending to swim upward or downward at the time, the effect of deflecting the balancer cilia away from the midline is an increase or decrease, respectively, in the frequency of beating of the balancer cilia. Each beat of the balancer is continued as a wave of ciliary beat along the ciliated groove, continued along the comb row. Therefore the frequency of beats is not the same on opposite sides of the animal. As a result, the animal turns like a paddle steamer with differing speeds of paddles (Fig. 4).

In contrast to a nervously controlled reflex of a higher animal, the sensory mechanism of the ctenophore's geotactic response is the mechanical sensitivity of a group of cilia, carried via the ciliated groove to the cilia of the combs (see below). The system is intermediate in complexity between those controlling protozoan responses, all within one cell, and those in higher animals mediated by nerves. Nevertheless, the ctenophore geotactic response is not rigidly fixed, for one animal can at different times swim upward or downward, depending on whether the balancer cilia are accelerated by a deflection in one direction or in the opposite direction. No mechanism has yet been found for the control of this long-term change in the sign of receptor sensitivity. 


\section{B. Transmission of the Ciliary Wave along the Comb Rows}

\section{STRUCTURE OF COMB PLATES}

The comb rows (Fig. 5A) consist of rows of comb plates (Fig. 5B). The great cilia of the combs are borne at the ends of cells (called Polster cells by the early authors), which are more than $100 \mu \mathrm{m}$ long but only $10 \mu \mathrm{m}$ wide and which reach down to the mesoglea (Figs. $5 \mathrm{C}$ and D). Between each group of Polster cells is a region of more typical epithelium, except that in Leucothea (and some related species) there is a specialized tract of ciliated cells between the comb plates.

Each Polster cell bears 15 to 40 cilia, each with its own membrane, adhering together to form a compound cilium more than $1 \mathrm{~mm}$ long. Polster cells contain ciliary roots, longitudinal fibers, a nucleus, many giant mitochondria up to $10 \mu \mathrm{m}$ long, and numerous vesicles and lipid droplets. The mitochondria have tubular cristae when fixed with osmic

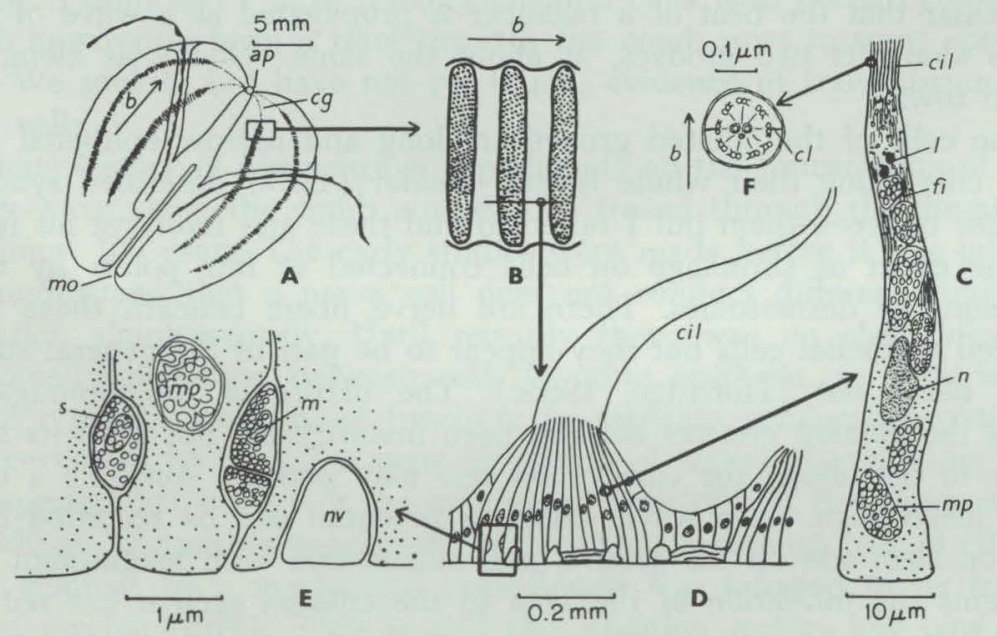

Fig. 5. Structure of comb rows and comb plates. (A) The whole animal Pleurobrachia; (B) enlargement of region shown in A, showing three comb plates; (C) a single ciliated cell; (D) a section taken along the comb row and transverse to the comb plate, showing fused cilia, cell boundaries, and location of nerve fibers; (E) detail of the region shown in $\mathrm{D}$, with synapses and cytoplasm of ciliated cells marked by dots; (F) transverse section of a cilium showing direction of the power stroke in relation to the position of the compartmenting lamellae (cl). ap, Apical organ; b, direction of power beat of cilia; cg, ciliated groove; cil, cilia; fi, fibrils in ciliated cell; $\mathrm{l}$, lipid droplet; $\mathrm{m}$, mitochondrion in nerve fiber; mo, mouth; $\mathrm{mp}$, mitochondrion in ciliated cell; $\mathrm{n}$, nucleus; $\mathrm{nv}$, axon sections; s, synaptic cleft. 
acid; their large size and abundance suggests great metabolic activity.

When a group of balancer cilia beats it originates a wave of ciliary beating that runs along the two ciliated grooves at the head of which the balancer stands. The majority of the cells along the ciliated groove and the comb row belong to one family of cells which have cilia distinguished by compartmenting lamellae (Fig. $5 \mathrm{~F}$ ). The power stroke of the beat is toward the apical organ and in the opposite direction to the wave of activity (i.e., the wave is antiplectic); the central fibrillae of each cilium are oriented at right angles to the direction of the beat. These waves of beats propel the animal slowly along with the mouth in front.

\section{THE CILIATED GROOVES}

The ciliated grooves are tracts of ciliated cells, a few cells wide, that run from the cells bearing the balancer cilia to each of the comb rows. Each of the four groups of balancer cells stands at the head of two ciliated grooves, and in living material one can readily see under a binocular that the beat of a balancer is propagated as a wave of cilia beats along its two grooves, at about the same velocity as along the comb rows.

The cells of the ciliated groove are long and narrow epithelial cells with cilia along their whole length. Heider (1927) described syncitial bridges between them but I failed to find these and interpret his result as the effect of shrinkage on cells connected at few points by tight junctions or desmosomes. There are nerve fibers beneath these long ciliated epithelial cells but they appear to be part of the general superficial nerve net (Horridge, 1965c). The nature of the propagation along the ciliated grooves has not been investigated, but from its similarity to that along the comb rows one may perhaps conclude a common mechanism. As a wave passes, a potential can be recorded by a suction electrode on the groove, and anaesthesia with magnesium ions prevents the inhibition of the beat in the ciliated groove but not the conduction of the ciliary waves along it.

\section{ANATOMICAL PATHWAYS ALONG THE COMB ROW}

Several possible pathways of transmission of the forward ciliary wave of the comb row have been found histologically: (a) nerve fibers beneath the ciliated cells, (b) the ciliated cells themselves, and (c) other cells that lie along the comb row between the comb plate cells. There is also evidence that ciliary waves are conducted mechanically from comb plate to comb plate. 
The nerve fibers apparently all belong to one nerve net when examined in methylene blue preparations and have only one type of synapse upon the ciliated cells when examined with the electron microscope. The simplest assumption is that the nerve fibers in the comb rows all subserve the reflex in which the comb rows are inhibited by a stimulus anywhere on the body surface (Bauer, 1910; Horridge and Mackay, 1964; Horridge, 1965c).

The ciliated cells themselves adhere closely together and nothing like a specialized junction or anastomosis has been found between them. There is not even an obvious line of desmosomes binding the cells together where they meet at the epithelial surface (Horridge and Mackay, 1964). In Leucothea there is a tract of ciliated cells stretching along the comb row in the spaces between the comb plates, but in Beroë, Pleurobrachia, and Cestus unspecialized epithelium lies between the comb plates. Possibly, therefore, there are two mechanisms, in different groups of ctenophores, for transmission of the ciliary wave.

No other types of cell have been described thus far in the comb rows, but Dr. Tamm and I have found elongated cells with dense cytoplasm which apparently form a tract beneath the comb rows in some species only. We sought, but have not yet found, evidence of transmission via these cells.

A long history of inconclusive experiments on the transmission of the ciliary wave along the comb now can be traced through the literature for almost 100 years. The early studies were made before it was generally understood that a nerve cell does not conduct different kinds of excitation simultaneously. Until recently there was no clear idea of cell-to-cell conduction between cells in other epithelia, no experience of the typical separation of functions in separate conducting systems, as necessitated by the all-or-none properties of waves of excitation, and an imperfect knowledge of the anatomical substrate in the comb rows. In addition, arguments were based on fallacious reasoning (e.g., a ciliary wave stopped by a mechanical impediment was inferred to be transmitted mechanically). That is still the situation today, but now the problem is seen to be a technical one. The connections of the ctenophore neurons are not known in sufficient detail; adequate microelectrode studies on the epithelial conduction have yet to be carried out, the contributions of different cell types have to be assessed in tissues where they are mixed, and, most significantly, the mechanical sensitivity of the cilia has not been measured in hydrodynamically controlled conditions. Furthermore, the common species used for physiological work, Mnemiopsis, Beroë, and Pleurobrachia, are not necessarily identical in the relevant features, so that arguments based on one do not neces- 
sarily apply to the others. The following topics require revision or extension to other species.

\section{MECHANICAL IMPEDIMENT OF COMB PLATES}

In the old literature are references to the interruption of the wave along the comb row by mechanically preventing one comb from beating (Verworn, 1890; Samassa, 1892; Parker, 1905; Child, 1933). This result was taken to prove that each comb plate passes on the wave to the next by mechanical drag forces. However, holding the comb plate may modify the physiological state (such as membrane resistance or potential) of the ciliated cells. Therefore mechanical impediment could interrupt cell-to-cell transmission along the comb row by acting indirectly.

\section{TRANSMISSION INDEPENDENT OF MOVEMENT OF CILIA}

Some authors (Parker, 1905; Child, 1933) have found that waves travel along comb rows (a) across a region where movement is prevented, (b) without mechanical contact between comb plates, and (c) across a region of the comb row where a lesion was healed and comb plates are absent. The first comb plate of the row is also clearly stimulated by an impulse of some nonmechanical nature which is transmitted along the ciliated groove. These observations show that some kind of subsurface conduction can occur.

\section{NEUROID CONDUCTION}

Transmission of ciliary waves along the comb rows was called "neuroid conduction" by Parker (1905) working on Mnemiopsis and Pleurobrachia. In addition to observations (a) to (c) above, Parker observed that (d) local cooling can prevent the beat locally without stopping transmission. Parker seems to imply cell-to-cell transmission athough he was aware that Hertwig (1880) had described fibers that could be nerves as running along the comb plates beneath the ciliated cells. The confused topic was summarized shortly after by Mayer (1912) who was closer to these events than we are today: "Samassa (1892) was unable to demonstrate the existence of a nervous system in Ctenophores. ... The experiments of Parker on Mnemiopsis lend support to the conclusion that nervous elements may extend outward from the apical sense organ along under the combs of cilia." Mayer, a man with wide experience with conduction in jellyfish tissue, therefore gives a totally different interpretation from that usually derived from work of that period. Mayer distinguishes clearly between this coordination along 
the comb row and the evidence of nervous inhibition of the beat at all points along the comb when any other part of the animal is stimulated, quoting Bauer (1910) and confirming with his own observations. This distinction was not appreciated again until recently. There was, however, in this early work no discussion as to whether one nerve net or one set of nerve fibers could serve the two functions of transmission of the ciliary wave and propagated inhibition of the cilia.

\section{RECENT OBSERVATIONS}

Recently, Sleigh (1968) showed that in Pleurobrachia the velocity of a forward ciliary wave depends on the interval since the previous wave and suggested that residual depolarization in the conducting elements influences the onset of the next excitation. This observation, however, still leaves open the question whether the ciliary wave is caused by mechanical drag forces, conduction by the epithelial cells along the comb row, conduction by specialized non-nervous conducting cells lying between comb plates, or by typical nerves which may run along the comb rows. Effects of ions and drugs could also be explained by any of these mechanisms, for even the mechanical interaction theory depends on the latency of the physiological response.

A few successful microelectrode penetrations of comb-plate cells, among many unsuccessful attempts, have been made in Cestus (Horridge, 1965a); confirmation in other species has proved impossible, although attempted several times. A sharp depolarization up to $27 \mathrm{mV}$ was recorded at the moment of the power stroke, followed by a slow recovery which occupied about 5 seconds. Beats at shorter intervals than this were accompanied by potentials that stood upon the falling phase of the previous potential. The magnitude of the depolarization was graded in accordance with the strength of the power stroke (Fig. 6).

Little can be said about the significance of these potentials for the following reasons. (1) It is not clear whether the potentials are the cause or an inconsequential side effect of the beat. (2) The potentials should certainly be confirmed, but they are not likely to be movement artifacts because the depolarization persisted long after the comb plate had come to rest. (3) No evidence has been presented that the potentials are propagated. (4) Since the penetrations were made into comb plates of mixed tissues, with most efforts unsuccessful, it is feasible that cells other than the ciliated cells were penetrated.

If, however, these graded depolarizations participate in some way in controlling the amplitude of the beat, a number of properties of the system can be explained. Sleigh interpreted his finding that waves at 

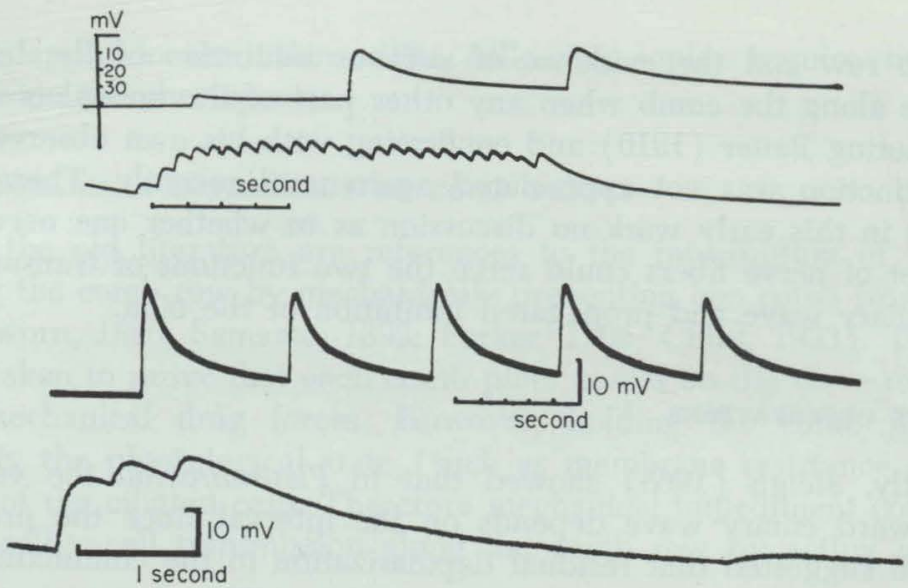

Fig. 6. Recordings, believed to be intracellular, from comb plate cells of Cestus. Note that the depolarization of the cell lasts much longer than the individual beat of the cilia and therefore potentials stand upon previous ones progressively more as the frequency is increased. There is no sign of a refractory period or all-or-none response and the height of the potential does not depend only on the interval since the previous beat. The potentials were correlated visually with the corresponding beat of the cilia (Horridge, 1965a).

high frequency have a higher velocity by suggesting that the latency is influenced by the residual depolarization in each comb plate along the line. Ouabain, which blocks sodium channels, has an effect on the velocity, possibly by influencing the membrane potential. Any damaged comb plate acts as a pacemaker possibly on account of being depolarized. At present one cannot say whether the propagation of the wave depends on the mechanical triggering from plate to plate in some instances when the comb plates are sufficiently close together and the beats are of large amplitude, or whether the agent is an electrical conduction through the tissue. Certainly there are ctenophores in which the comb plates are so far apart and the beat sometimes so weak that a mechanical triggering of the beat seems impossible. Further study may reveal that special conducting systems in the tissue do not occur where the comb plates are close together, but we still have to explain the control of amplitude and the propagation from the ciliated groove as nonmechanical. The ciliated cells are very long and thin, and synapses upon them from fibers of the superficial nerve net are presumably responsible for the propagated inhibition of the beat. The fact that these synapses are at least $100 \mu \mathrm{m}$ from the cilia themselves suggests that the tendency to beat is influenced by the membrane potential of the ciliated cell. 


\section{REVERSE WAVES ALONG THE COMB ROWS}

Reverse waves, which occasionally pass toward the apical organ in some ctenophores with closely spaced comb plates, are different in transmission properties from forward waves, although it is usual for a reverse wave and a forward wave to cancel each other when they collide. Contra Child (1933), the direction of the effective stroke is still toward the apical organ in reverse waves. The cilia touch the next along the line in the course of a reverse wave, which probably is propagated mechanically because (a) the velocity of reverse waves is almost independent of wave frequency and (b) Ouabain has little effect on the velocity of reverse waves but alters the velocity of forward waves (Sleigh, 1968).

\section{THE SUPERFICIAL NERVE NET AND INHIBITION OF THE CILIA}

Over the whole surface of ctenophores investigated there is a scattering of multipolar nerve cells with axons that appear to form a polygonal nerve net (Heider, 1927). Apart from the fact that the net stains readily with methylene blue, the evidence that it is a conducting system is almost nonexistent. A touch to any region in all ctenophores causes a sudden arrest of the waves of ciliary action along the comb rows. This also occurs in small pieces of the animal, and transmission is not prevented by any pattern of cuts. There is a single sharp threshold to a single electrical stimulation and the velocity of transmission is $30-50 \mathrm{~cm} / \mathrm{sec}$ in Cestus (Horridge, 1966). Further stimulation causes first local and then general contraction of muscles which retract the comb rows or lobes of the body. This action on ciliated cells and muscles is blocked by excess $\mathrm{Mg}^{2+}$ ions. The evidence therefore favors the view that the ubiquitous system which conducts the ciliary inhibition is a superficial nerve net rather than the epithelial layer itself, but more direct proof is required.

One anatomical feature that is very relevant to the control of the cilia and the mechanism of transmission of the wave along the comb row is that all synapses upon the ciliated cells lie at the basal end of the ciliated cells, at least $100 \mu \mathrm{m}$ from the cilia. This location strongly suggests that the tendency of the cilia to be excited in any way is controlled by the membrane potential of the cells which bear the cilia.

\section{Fingers of Leucothea}

The common ctenophore Leucothea is covered with fingerlike protrusions, $1 \mathrm{~cm}$ long when extended, all over its delicate body (Fig. 7). 
A

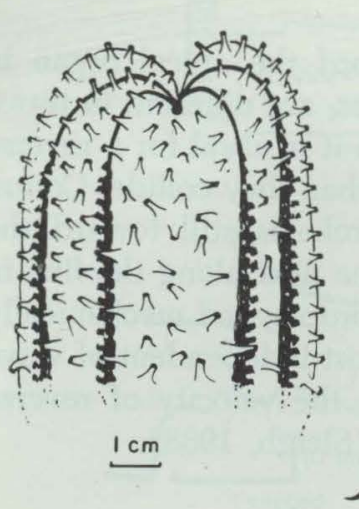

B

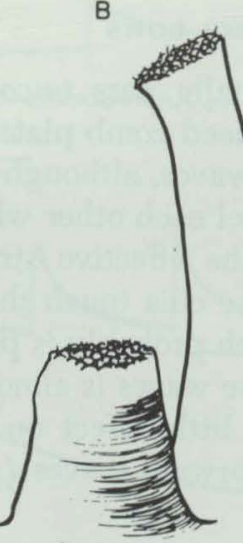

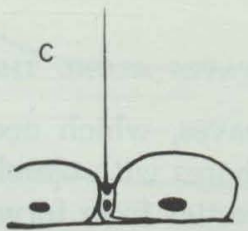

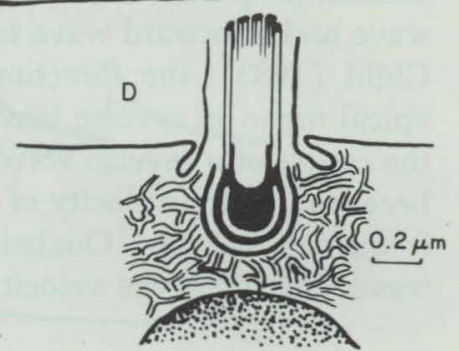

Fig. 7. Details of the fingers of Leucothea. (A) The apical end of the whole animal, showing fingers distributed over the body surface. (B) A finger in the short relaxed condition and then extended by contraction of circular muscle which acts on the solid core of mesogloea. (C) Epithelium with nonmotile receptor cilium between gland cells as in Fig. 8. (D) Basal body of nonmotile cilium as in Fig. 9.

When the surrounding water is still, these fingers are contracted, but the slightest vibration in the water nearby causes them to extend suddenly.

\section{TIP OF FINGER}

The epithelium of the flat ends of the fingers (Fig. 8) is composed of (a) numerous gland cells which secrete a toxic mucus that is capable of paralyzing small crustaceans at a touch, (b) sensory neurons of several kinds, (c) subepithelial nuerons forming a plexus, (d) muscle fibers, and (e) unspecialized epithelial cells (Horridge, 1965b).

\section{NONMOTILE LONG CILIA}

Long, stiff, and straight cilia, the "lange dünne Tastborsten" of Hertwig (1880), are the most likely candidates for the extremely high sensitivity of Leucothea fingers to minute displacements in the surrounding water. The cilium, up to $100 \mu \mathrm{m}$ long, has the typical $9+2$ arrangement of fibrillae, often with minor anomalies as if the exact structure is not critical.

The peculiar structure of this nonmotile cilium invites speculation as to its mechanism. The basal body is specialized as a series of three concentric shells which stain heavily like cilium root material, the outer 


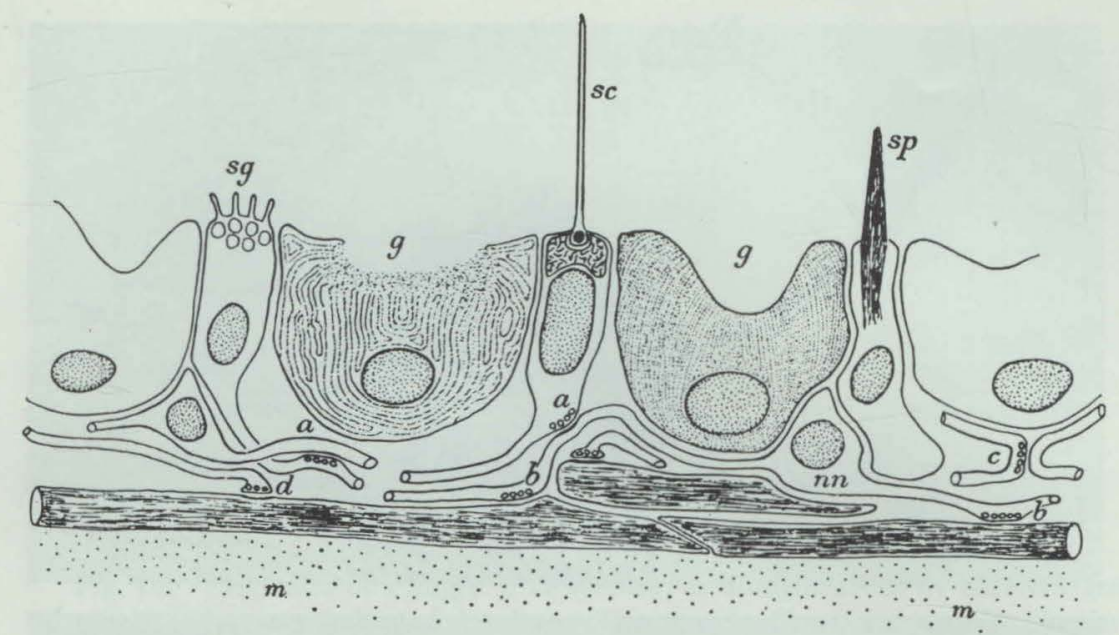

Fig. 8. Cells and synaptic contacts thus far observed in the finger-tip epithelium. Receptor neurons are shown between the large gland cells. Synapses are indicated as a row of vesicles, as follows: a, sensory cell to internuncial; b, internuncial to muscle cell; c, unkonwn to unknown; d, unknown to muscle cell. g, gland cell; m, mesogloea; nn, nerve-net neuron; sc, long nonmotile cilium; sg, short/grouped cilia; sp, sensory peg (Horridge, 1965b).

shell being $500 \mathrm{~mm}$ in diameter (Fig. 9). The cytoplasm around this root is crowded with a mesh of tubules which are probably in continuity with the outside of the cell. That the cell bearing the cilium is sensory is indicated by its possession of an axon which joins the ectodermal nerve net. The shaft is clearly closely coupled to the motion of the water. One suggested mechanism of action is that the basal body is a ball and socket in which relative motion causes current to flow (or leak) from the surrounding mass of tubules out through the shaft of the cilium. No similar structure is known elsewhere in the animal kingdom.

The tip of the finger also carries cells which bear short stubby nonmotile cilia and other cells which extend as thick pegs $100 \mu \mathrm{m}$ long and 15-20 $\mu \mathrm{m}$ thick. Their function is unknown; possibly they assist the deadly action of the fingers, which poison any passing copepod that they strike.

\section{CONTROL OF FINGER RESPONSES}

The fingers of Leucothea shoot out symmetrically in response to vibration in the water by the contraction of the circular muscle of their column (Horridge, 1965b). On the other hand, a touch to the body wall near a finger causes it to bend toward the stimulus by the action of longi- 

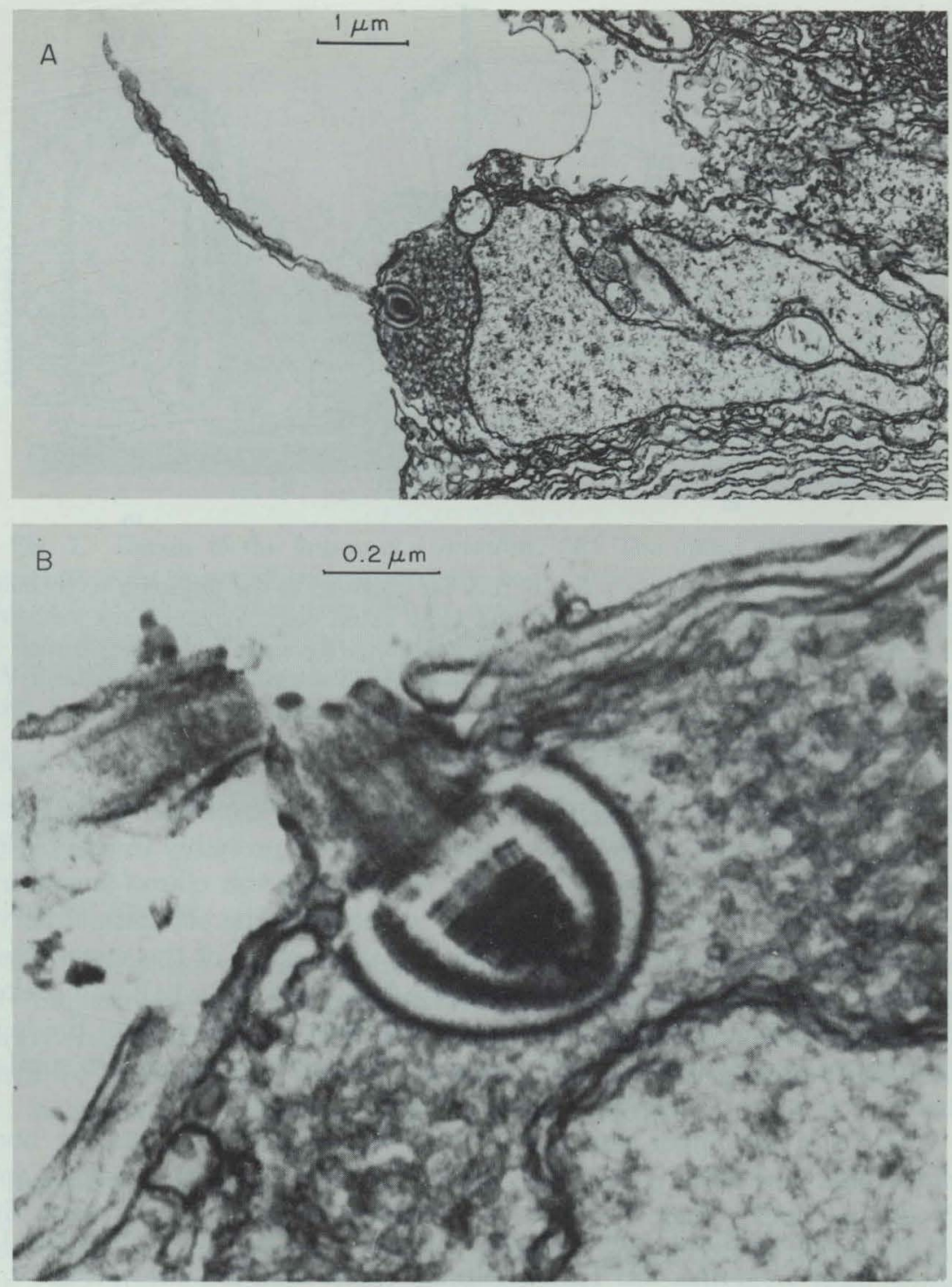

Fig. 9. Nonmotile cilium of the epithelium of the finger tip of Leucothea, in longitudinal section. (A) The cilium projecting from the distal part of a specialized cell. (B) Enlarged view of the three concentric shells of the basal body, surrounded by a mass of tubules. 


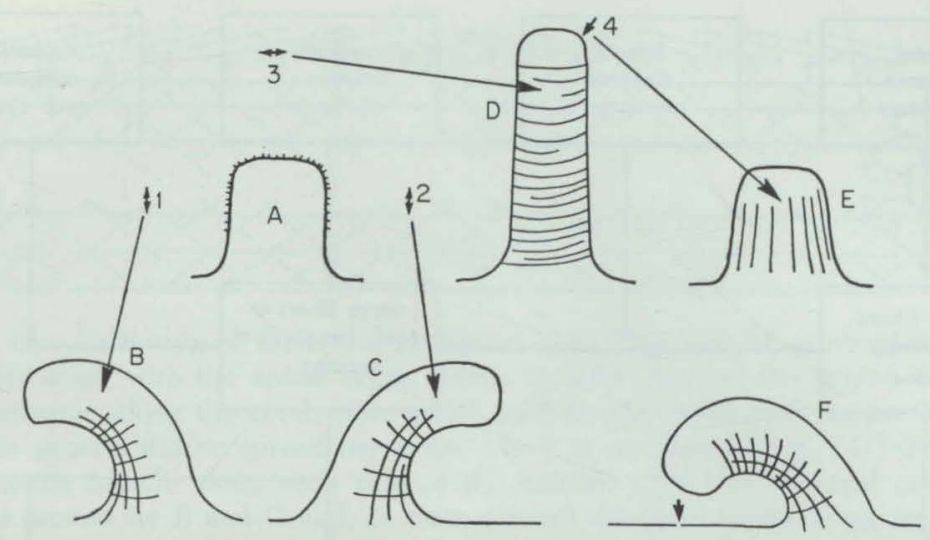

Fig. 10. Responses of a finger of Leucothea, as brought about by different groups of muscles that are indicated by lines. The muscle fibers are mainly circular or longitudinal and lie in the mesoglea and the fingers contain no endoderm. In A, a vibratory stimulus at 1 or at 2 causes sideways extension as in B or C, a vibratory stimulus at 3 causes straight extension as in D. In each case the finger extends toward the vibration. Electrical stimulation 4 causes retraction to $\mathrm{E}$, and $\mathrm{F}$, any stimulation of the nearby ectodermal surface causes bending toward the point stimulated.

tudinal muscle on that side. A vibration in the water at the side of the finger causes it to shoot out and bend simultaneously (Fig. 10). In all these responses the finger acts as a perfect example of an independent effector.

When we look at the available machinery which could coordinate these responses we find an incomplete picture. The vibration receptor cells send axons to the subepithelial plexus where they make polarized synapses with other axons. Some of these other axons, not necessarily the same ones, make polarized synapses with muscle fibers. The following points have not been determined: (1) whether different types of sensory cells make indiscriminate connections with other neurons or whether they have separate pathways to particular directions of muscle fibers; (b) whether sensory axons connect with other similar sensory axons or only with interneurons; (c) whether sensory axons connect directly with muscle fibers; (d) whether true nerve-net neurons exist; and if so (e) whether there are several distinct types of nerve-net neurons or separate overlying nerve nets. Elsewhere, other synapses between nerve cells and mesenchyme cells have been found (Hernandez-Nicaise, 1968).

A formal model of the minimum connections necessary for the responses to be performed can readily be drawn up (Fig. 11). Careful consideration of this "black box diagram," however, shows that it is no more 


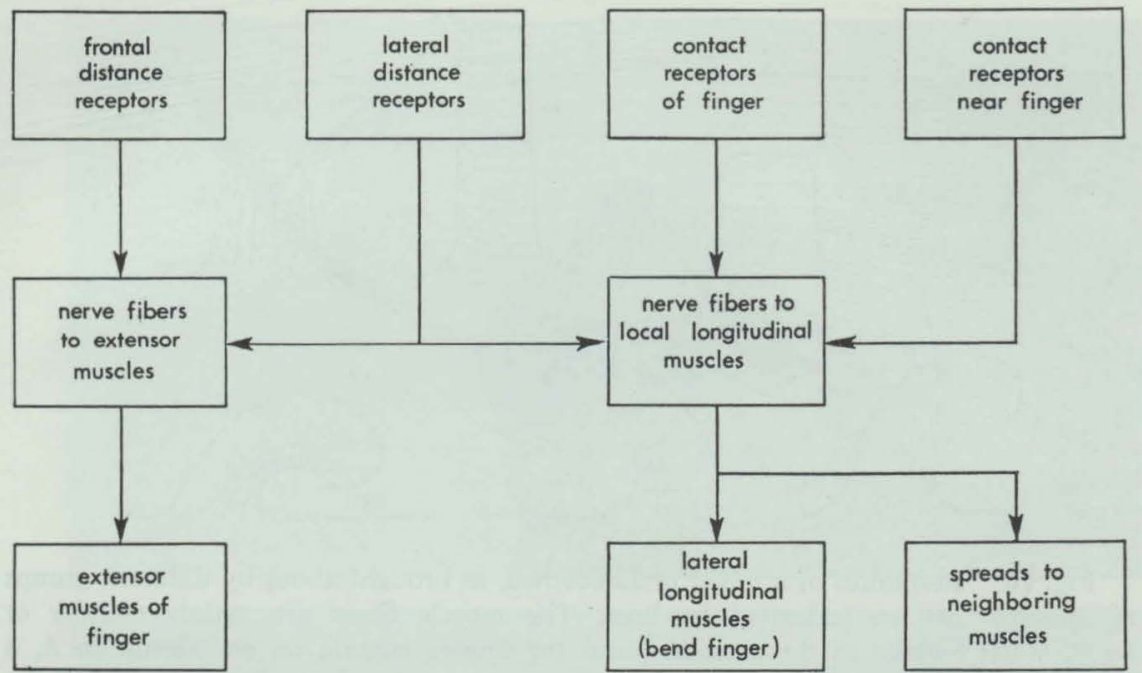

Fig. 11. A diagram of the inferred connections between the sensory cells, epithelial nerve cells, and muscle cells, required to explain the responses of an individual finger. Two types of connection of receptors are required: (a) finger tip receptors to cause symmetrical extension by circular muscles and (b) lateral and neighboring receptors to local longitudinal muscles to cause sideways bending.

than a pictorial representation of the physiological observations on which it is based. Its use is to draw attention to the need for independent anatomical confirmation of the proposed physiological pathways from the receptors to the effectors.

\section{Swimming of Cestus}

The long ribbon-shaped Cestus and Vexillum swim by slow sinusoidal undulations of the whole body. In an animal $30 \mathrm{~cm}$ long the oscillation is typically about 1 per 3 seconds; the velocity of the wave is about 11-18 $\mathrm{cm} /$ second in the muscle, the amplitude about $5 \mathrm{~cm}$, and the creature advances at about the wave velocity divided by 2.8 (Pfitzner, 1962). Muscle fibers running lengthwise form a thin sheet of muscle which covers both flat sides of the animal. The muscle sheets of the two sides act on the hydrostatic skeleton of the mesoglea. A single shock applied to either muscle sheet causes a propagated contraction which runs along that side of the animal. At the same time a wave of inhibition of the comb-plate beating spreads over the whole animal but at a much greater velocity than the muscle response. Clearly there are at least two separate 


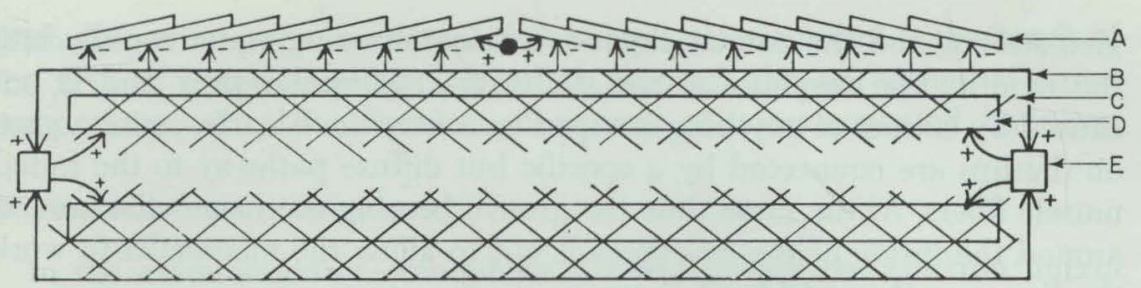

Fig. 12. Pathways of excitation in Cestus. (A) The line of comb plates along the upper edge, with the apical organ shown in solid black at the center. (B) The rapid pathway, along the comb row, which inhibits the beating of the comb plates. (C) The general diffuse spread nerve net which is connected to B. (D) The sheet of swimming muscle along each side of the animal. (E) The terminal pacemaker which is excited by B and C and, in turn, sets off alternate waves along the muscle sheet of the two sides. Note that all pathways are unpolarized but that the action of one pathway on another is always polarized.

conducting systems (Horridge, 1966), but there is no reason to suppose two overlapping nerve-net systems for ciliary inhibition and for muscle waves, because the latter could be conducted by the muscle fibers themselves.

A pacemaker for the swimming oscillation is situated at each end of the animal (Fig. 12). When any part of the animal is stimulated, either end starts to oscillate and increases in amplitude while the stimulus continues. When the pacemakers at the tips are cut off and the animal is stimulated vigorously, it will still swim because a new pacemaker forms at the cut end. The pacemaker action could well reside in the muscle cells themselves. The swimming wave is transmitted readily along the animal but appropriate cuts reveal that it is transmitted with difficulty across the muscle fibers (Horridge, 1966). Muscle waves travel equally well in each direction and usually cancel where they meet, but a large wave can pass through and cancel a small wave. Muscle waves and their pacemakers cannot be brought to a halt by stimulation, whereas the ciliary waves are always inhibited by any stimulation. Apparently the swimming is an escape response and is not controlled in any way by the statolith, although one might expect swimming to be directed in relation to gravity.

\section{E. The Feeding Response of Beroë}

Beroë swims with the mouth in front. If the lips come into contact with a Pleurobrachia (another species of ctenophore) the Beroë opens its mouth and gives a great gulp. The gulp is caused by the contraction of radially arranged muscle fibers throughout the whole animal. The meso- 
glea stiffens and the animal expands in size, drawing water rapidly into the mouth. The response is specific to this particular prey and is not caused by extract of anything except Pleurobrachia. Clearly, sense organs on the lips are connected by a specific but diffuse pathway to the radial muscle fibers. At the same time the groove bearing the macrocilia around around the inside of the lips spreads out to allow the macrocilia to work the lips over the outside of the prey.

\section{THE NERVOUS SYSTEM OF CTENOPHORES}

\section{THE SUPERFICIAL NERVE NET}

The superficial nerve net identified by Hertwig (1880) by treatment with osmic acid, and subsequently described by Heider (1927) by vital staining with methylene blue, has not in fact been demonstrated as nervous by physiological methods. It is only an assumption that the axons, synapses, and sensory cell bodies seen by electron microscopy are the same branched neurons that spread as a net over the whole surface. Only by analogy with higher animals are the synaptic vesicles thought to have this function and to be presynaptic.

Anatomical synapses, with vesicles in the axon, occur between axons and muscle fibers, both of which may lie freely in the mesoglea (Horridge, 1965b). Similar anatomical synapses occur between the neurons of the superficial epidermal nerve net, which spreads over the entire surface and is concentrated into strands beneath the comb rows. Beneath the comb rows are numerous anatomical synapses between neurons and the bases of the ciliated comb-plate cells (Horridge and Mackay, 1964). Excitation which appears to be nervous (because it can be anaesthetized by $\mathrm{Mg}^{2+}$ ions) is propagated across the general epithelium and inhibits the beating of comb-plate cilia. Therefore the synapses (and by inference the whole epithelial nerve net) is supposed to be the transmission system for this inhibition. There is no support, from either methylene blue staining or electron microscopy, for axon arborizations reaching as far as the bases of the cilia, as described by Korn (1959).

In the case of certain coordinated responses, such as those of individual fingers of Leucothea, or the feeding response of Beroë, it can be inferred, from the separation of functions, that distinct pathways are present in the superficial nerve net. In other examples, such as the protective withdrawal of the comb rows in many species and the initiation of swimming in Cestus, the response cannot be elicited without the inhibition of the ciliary waves, so that one nerve net will serve for both. 
With this assumption, cessation of the comb-plate activity is the result of the first, or a few impulses spreading through the nerve net, whereas the withdrawal or the swimming response requires repeated impulses.

\section{SYNAPSES IN CTENOPHORES}

In the examination of ctenophore material under the electron microscope one finds, in places where nerve fibers and synapses are expected, structures closely resembling synapses of higher animals. There is a characteristic synaptic cleft, $10-12 \mathrm{~m} \mu$ wide with increased staining of the membranes on either side. A row of vesicles $35-45 \mu \mathrm{m}$ in diameter are packed against the membrane of the cleft on one side only, usually trapped between the cell synaptic membrane and a structure resembling an empty mitochondrion within the nerve terminal (Fig. 1B).

These structures occur quite consistently in all ctenophores examined, and the obvious conclusion from their structure and location is that they are synapses of the nervous system. Once this part of the circular argument is accepted the synapses become the best means of identifying nerve fibers.

The postsynaptic cell can be a nerve fiber, a muscle fiber, a ciliated cell, gland cells of the endoderm (possibly photophore cells), or mesenchyme cells (Horridge, 1965b; Hernandez-Nicaise, 1968). The presynaptic component is usually interpretable as a nerve fiber, but realistic synapses have also been found with a muscle cell as the presynaptic element. No differences have been noticed between presumed inhibitory synapses upon ciliated cells and presumed excitatory ones upon muscle or nerve cells.

\section{NERVE FIBER RECOGNITION IN CTENOPHORES}

The following, in order of reliability, are features for identification of ctenophore nerve fibers in electron microscopy: (a) continuity with a sensory cell, (b) presence of a synapse, and (c) as hollow tubes parallel to the mesoglea containing neurotubules and vesicles of $30-50 \mathrm{~nm}$ diameter. Because these conditions are not adequately met, most hollow tubes thought to be nerve fibers cannot be identified with certainty in electron micrographs; equally unhelpful, they stain poorly with classic silver methods and erratically with methylene blue. In general, Heider's (1927) account has been confirmed repeatedly in my own studies, but basically we know little more than the existence of a superficial net with concentration of fibers beneath the comb rows. This is an inadequate basis for identifying pathways of excitation, let alone details of mechanisms. 
Neuromuscular junctions can be seen in living material as definite endings of single axons upon isolated muscle fibers in the mesoglea. At higher magnification the identification is more convincing. Vesicles 30 $50 \mathrm{~nm}$ diameter are lined up on the axon side of an obvious synaptic cleft with thickened membrane resembling a neuromuscular junction of higher animals. This is almost the only evidence that excitation is transmitted to muscles by neurons, and the alternative, of transmission from muscle cell to muscle cell, has not been ruled out. The fact that discrete neuromuscular junctions are far from each other on a long muscle fiber suggests that the muscle fiber must transmit excitation along its own length, for it is readily observed in life to contract as a whole.

\section{CRITERIA OF NONRANDOM CONNECTIONS IN A NERVE NET}

A nerve net is defined as a plexus of nerve cells in which any part of any cell can act vicariously for any other. Therefore, in a nerve net there is only one type of nerve cell as judged by the pattern of connections, functionally only one type of excitation is transmitted in any one region of the net, and physiologically there is only one set of parameters such as threshold and velocity of transmission at any point. Within these limits there may still be regional diversity in sensitivity and velocity of conduction or in the neuron shapes and their arrangement. However, any advance above this level of complexity implies two or more types of nerve cell which recognize each other as distinct, as shown by their failure to form indiscriminate connections. The existence of two types of excitation which run eventually to different effectors implies two distinct pathways which may intermesh and even interact, but which remain essentially separate. It is this differentiation of neuron types which makes possible the evolution of a central nervous system in higher animals. Locally such separation has been inferred in a very simple independent effector, the fingers of Leucothea (Horridge, 1965b), but as yet a morphological confirmation is lacking.

\section{INDICATIONS FROM CTENOPHORES ABOUT THE ORIGIN OF THE NERVOUS SYSTEM}

Ctenophores have only a generalized nerve net which is usually not separated into distinct overlying nets subserving different functions at any one point. In addition they have other response systems, some with cell-to-cell conduction. This places them on about the same level as hydrozoan polyps, but less complicated in nervous organization than most coelenterates.

From the ctenophore organization we can infer: 
(a) The nerve cells contain vesicles and secretions typical of nerve cells throughout the animal kingdom. Chemical affinity to methylene blue, and heavy metals such as osmium and silver, also illustrates the remarkable ubiquity of the chemical characters of neurons throughout the animal kingdom.

(b) The most highly evolved neurons in ctenophores are the sensory cells.

(c) Pacemaker cells are found in the most primitive conducting systems, and they are not necessarily neurons.

(d) Inhibition appears at this lowly level.

(e) Local reflexes integrated by local specialized regions of the nerve net, e.g., in tentacles, lips, fingers, and retraction of lobes, readily become specialized once the nerve net is evolved.

(f) Other conducting pathways that are functionally distinct from the nerve net can readily be made available by cell-to-cell conduction in an epithelium, as possibly in comb rows and the muscle sheets of Cestus which swims by undulations. Whether or not cell-to-cell conduction is more primitive than the nervous system, these systems have evolved separately, usually as part of a locomotory mechanism.

(g) There are no two-neuron arcs in any simple reflex. Sensory cells apparently activate a region of the nerve net, from which there are numerous branches to many muscle fibers. This suggests that neurons did not evolve singly but in aggregations of cells that act in unison (Horridge, 1968).

\section{MACROCILIA OF BEROË}

A structure that appears to be unique in the animal kingdom is found on the edge of the mouth of Beroë (Horridge, 1965d). Inside the lip, in a wide band, each cell carries a thick projection which bends actively. with a movement like that of a cilium. The projection, called a macrocilium, consists of two to three thousand ciliary shafts of the typical $9+2$ pattern arranged in a regular hexagonal parallel array within a single membrane (Fig. 13). The power stroke is toward the stomach and the function is clearly to work the edge of the mouth over large prey such as Pleurobrachia, upon which Beroë feeds. Gland cells and sensory cells occur in the same region.

Although these remarkable organelles present numerous problems related to the growth and mechanism of cilia, only one piece of work has thus far utilized them (Horridge, 1965d). The macrocilia were fixed 

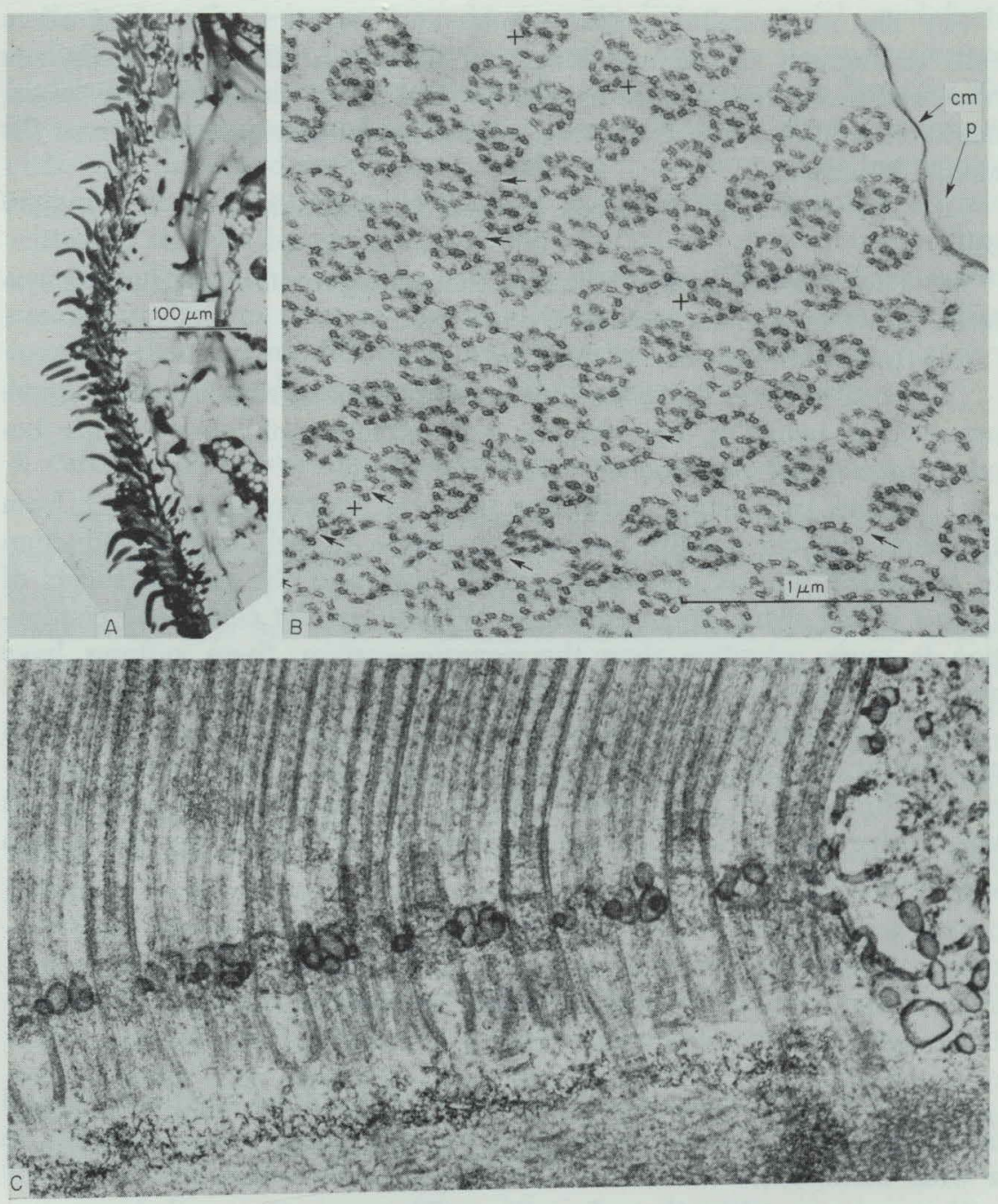

Fig. 13. Macrocilia of Beroë. (A) Light micrograph of the inner surface of the lip showing macrocilia fixed in the act of bending. (B) The basal body region in longitudinal section. At one particular level, where the 9 doublets turn to triplets, there is a layer of tubules among the basal bodies; possibly these are the excitatory mechanism. (C) Transverse section through a macrocilium showing the regular pattern of bridges between the shafts. Most of the bridges, but not all, run at right angles to the direction $\mathrm{p}$ of the power stroke. The bridges are strong enough to cause distortion of the rings, as indicated by crosses, and it has been inferred from this that motion occurs by sliding along the two cleavage planes that run through none of the bridges. cm, Membrane of the macrocilium (Horridge, 1965b). 
while actively bending. If bending is brought about by active shortening of fibrils of the cilia on the concave side of the bend, it is possible to work out the theoretical increase in radius of ciliary shafts because the watery medium in which they lie must have a constant volume. However, changes in diameter of shafts are not apparent where the macrocilium is most actively bent. Another argument against shortening of cilia fibrillae is that of $40-50 \%$ decrease in length would be required. This is excessive in view of the $5 \%$ or so shortening that would be required in a normal cilium. Finally, cross-bridges which occur between fibrillae of different shafts are strong enough to distort the shafts and not to break during fixation. Based on this evidence it was suggested that movement is caused by active sliding between fibril pairs of each shaft in macrocilia, and this is a theory which may apply to all cilia and sperm tails. Evidence for this theory of ciliary motion is growing and nothing precludes it.

\section{CONCLUSIONS}

The contribution of ctenophores to problems of general physiological interest is undoubtedly the most appropriate topic with which to conclude. For although ctenophores are of enormous commercial importance as one of the major predators upon the larvae of food fishes, it is otherwise not apparent why time, space, and resources should be spent on one of the lesser phyla. The following topics, six related to cilia and eight to the origin of the nervous system, stand out from the above factual account in showing how general concepts emerge from the most unlikely corners.

1. Photoreceptors derived from cilia, found in several of the lowest phyla, illustrate how the basal body that can form a cilium readily has its synthetic mechanism modified to produce other structures. The increase in membrane to form the ctenophore lamellate bodies is, however, by lateral extension of the cilium, so that the final whorled structure resembling an onion is unlike any other presumed photoreceptor (Horridge, 1964a). Such a unique structure is generally accepted as indicating an independent evolution, but there remains the problem of what is the mechanism of differentiation on which this diversity of structure has evolved.

2. The mechanical sensitivity of motile cilia is readily demonstrated with the relatively enormous cilia of the comb plates. A comb plate when pushed responds with a power stroke. This property makes possible the 
propagation of a wave of ciliary activity by purely mechanical interaction, as is thought to occur in many examples of metachronal ciliary waves of both Protozoa and Metazoa. Whether the forward wave is actually triggered by mechanical interaction remains to be demonstrated in the various groups of ctenophores.

3. Extremely sensitive nonmotile cilia are readily available on the fingers of Leucothea and are widespread on other ctenophores. It is a moot point whether the sensitivity is a reversal of the coupling between the excitation of a cilium and its mechanical response. Modified cilia are found in the apical dendrite of many sensory neurons throughout the animal kingdom but in no instance is it clear why this is so. The peculiar structure of the basal body in the ctenophore examples suggests that a novel mechanism of mechanoreception awaits discovery, and that the primitive basal body from which it evolved was also mechanically sensitive.

4. Neural control of cilia is readily displayed in the sudden halt of the comb-plate waves. The synapses upon the ciliated cells are the most obvious path of this inhibition. The synapses, however, are at the opposite ends of the ciliated cells from the cilia and presumably exert their effect in the same way as better known synapses, by polarization of the postsynaptic cell. This mechanism awaits further analysis as a model of nervous control of cilia.

5. Ciliated "axons" of the ciliated grooves are elongated cells of the ciliated groove. They conduct the excitation initiating the beat from the apical organ to the beginning of each comb row. They are peculiar in that the cilia beat with a single stroke as the excitation passes, so the cells appear to be ciliated axons with an external sign of each impulse. They are also of interest in that their tiny cilia could hardly be adequate to excite mechanically the large cilia standing at the head of the comb. Therefore at least this stage in the transmission of the ciliary wave is apparently a nonmechanical conduction from cell to cell.

6. Macrocilia led to inference of sliding theory in cilia. Macrocilia are so thick that when they bend sharply it is quite obvious that sliding must occur between their constituent elements, unless we have an extraordinary elasticity not found in component fibrils of other cilia. Study of the bridges between fibrils in neighboring shafts led to the conclusion that the sliding must occur between fibrils within each ring of nine pairs. The plane of sliding as inferred from the direction of beat turned out to be the same as that derived independently from the study of the bridges (Horridge, 1965d).

7. Neurosecretory granules in primitive excitable cells. Among the 
cells of the apical organ are some that are packed with granules closely resembling neurosecretory products in appearance under the electron microscope and in staining properties (Horridge, 1965c). Although the apical organ has not the organization to justify the name of ganglion, it certainly contains numerous cells that act as receptors of external stimuli, e.g., gravity, vibration, and possibly light. For many years it has been suspected that secretions from the apical organ might be significant in controlling long-term behavior or growth (Hyman, 1940). If we wish to discuss which came first, neurons or neurosecretion, then it becomes necessary to understand the action in more detail of the control and effects of the secretion in apical organ cells that are presumed to be nonnervous because they lack axons.

8. The place of reflex systems in primitive animals. This topic is relevant to the discussion of whether behavior of primitive animals can be considered as derived from component reflex systems, or whether a reflex is a specialization which emerges from a total behavior pattern when one particular input-output relation has become automatic in its action and therefore easy to distinguish in experimental analysis. Ctenophores show that where a nervous system is found in its simplest form there are already specialized systems, e.g., in the feeding response of Berö̈, with predictable input-output relations, and that these systems are most clearly distinguished because they operate by functionally separate pathways of conduction. A part of the total nervous system, set aside for a particular job, works like clockwork and thus justifies the name of reflex, but such a limited circuit has clearly evolved from a more widespread general system.

9. Inhibition in a primitive nervous system. One can argue that possibly the most primitive conducting system for control of muscle contraction was by cell-to-cell conduction (Horridge, 1968). Therefore it is possible that the most primitive neurons acted on their target cells to inhibit them. A nerve net, however, must operate by successive excitations, which presumably came first, but there is no doubt that the most primitive nervous systems we know today contain inhibitory circuits. As in medusae, the inhibition in ctenophores is the stopping of an ongoing locomotory rhythm by any external stimulus that could lead to a feeding response.

10. Synapses similar to those in higher animals. There is an extraordinary similarity in the structures that are recognized as anatomical synapses throughout the animal kingdom, from ctenophores and cnidarians to the cortex of man. It is possible to explain this uniformity by suggesting that only one of many possible means of physiological trans- 
mission has been recognized thus far. However, a better explanation is that if one cell is to excite another by sudden release of a transmitter, there must be a synaptic cleft of a particular area and width, as fixed by the laws of diffusion, and the transmitter must be stored in vesicles behind a specialized membrane. Therefore the anatomy of a synapse follows from the physical properties of its components, so that anatomical synapses of similar appearance in different groups of animals could be the result of convergent evolution.

11. Cell-to-cell transmission was first discussed in ctenophores as "neuroid transmission," and it is of interest to see why there has been so little progress in the analysis of conduction of the ciliary wave along the comb row. To prove cell-to-cell conduction requires either a demonstration by microelectrode studies (which have proved impossible thus far) or an elimination of the underlying nerve fibers. A positive finding of mechanical interaction between cilia would be only a partial solution, for interaction within the tissue could be present in addition.

12. Separate pathways within a nerve net in one region are a sign of specialization between neurons. The neurons cannot be connected together indiscriminately if separate overlying lines of conduction are present. This separation is the earliest sign of neuronal specificity such that differences between growth patterns of neurons make possible the growth of a central nervous system.

13. The wiring diagram is inferred but not observed directly. It is quite hopeless, by present methods of neuron staining, or reconstruction from sections, to make out the "wiring diagram" or connection pattern that is responsible for impulse flow. This statement is even truer where the neurons are collected into ganglia. Even if the ramifications of the dendrites and axon arborizations were not too extensive to be followed in every detail, it is impossible to infer from the anatomy which synapses are functionally significant. On the other hand, as ctenophores show in a very simple way, one can infer possible "black-box" systems from physiological studies.

14. Giant mitochondria of the comb-plate cells of ctenophores reach $10 \mu \mathrm{m}$ in diameter and are mostly in the range 3-6 $\mu \mathrm{m}$ (Horridge, 1964b). They are so crowded that they almost fill the comb plate, and presumably this is the fuel injection system of the giant cilia. These highly specialized giant components offer some advantages for future analysis.

In conclusion, ctenophores are of interest for two general reasons. The highly specialized components of ctenophores, particularly those concerned with cilia, lend themselves to the elucidation of fundamental biophysical questions. The relatively simple nature of the coordination 
systems reveals general principles in the control and evolution of behavior, because in ctenophores it is possible to describe a greater proportion of the mechanisms than in higher animals.

Note added in proof. A paper published since this article was written will bring the reader up-to-date. Krisch, B. (1973). Uber das Apikalorgan (Statocyste) der Ctenophore Pleurobrachia pileus. Z. Zellforsch. 142, 241-262.

\section{REFERENCES}

Bauer, V. (1910). Über die anscheinend nervöse Regulierung der Flimmerbewegung bei den Rippenquallen. Z. Allg. Physiol. 10, 230-248.

Child, C. M. (1933). The swimming plate rows of the ctenophore Pleurobrachia as gradients, with comparative data on other forms. J. Comp. Neurol. 57, 199-252.

Chun, C. (1880). "Die Ctenophoren des Golfes von Neapel, und der angrenzenden Meeres-Abschnitte.” Engelmann, Leipzig.

Heider, K. (1927). Vom Nervensystem der Ctenophoren. Z. Morphol. Oekol Tiere 9, 638-678.

Hernandez-Nicaise, M. L. (1968). Specialized connexions between nerve cells and mesenchymal cells in ctenophores. Nature (London) 217, 1075-1076.

Hertwig, R. (1880). Ueber den Bau der Ctenophoren. Jena. Z. Naturwiss. 14, 393457.

Horridge, G. A. (1964a). Presumed photoreceptive cilia in a ctenophore. Quart. J. Microsc. Sci. 105, 311-317.

Horridge, G. A. (1964b). The giant mitochondria of ctenophore comb plates. Quart. J. Microsc. Sci. 105, 301-310.

Horridge, G. A. (1965a). Intracellular action potentials associated with the beating of the cilia in ctenophore comb plate cells. Nature (London) 205, 602.

Horridge, G. A. (1965b). Non-motile sensory cilia and neuromuscular junctions in a ctenophore independent effector organ. Proc. Roy. Soc. Ser. B 162, 333-350.

Horridge, G. A. (1965c). Relations between nerves and cilia in ctenophores. Amer. Zool. 5, 357-375.

Horridge, G. A. (1965d). Macrocilia with numerous shafts from the lips of the ctenophore Beroë. Proc. Roy. Soc., Ser. B 162, 351-364.

Horridge, G. A. (1966). Pathways of co-ordination in ctenophores. Symp. Zool. Soc. London 16, 247-266.

Horridge, G. A. (1968). The origins of the nervous system. In "Structure and Function of Nervous Tissue” (G. H. Bourne, ed.), pp. 1-31. Academic Press, New York.

Horridge, G. A., and Mackay, B. M. (1964). Neurociliary synapses in Pleurobrachia (Ctenophora). Quart. J. Microsc. Sci. 105, 163-174.

Hyman, L. (1940). "The Invertebrates," Vol. 1. McGraw-Hill, New York.

Korn, H. (1959). Zum Nervensystem der Ctenophore Pleurobrachia pileus O. Müller. Zool. Anz. 163, 351-359.

Mayer, A. G. (1912). Ctenophores of the Atlantic coast of North America. Carnegie Inst. Wash. Publ. 162, 58.

Parker, G. H. (1905). The movements of the swimming-plates in ctenophores, with reference to the theories of ciliary metachronism. J. Exp. Zool. 2, 407-423. 
Pfitzner, I. (1962). Zur Bewegung von Cestus veneris Lesueur (Ctenophora), eine Filmanalyse. Zool. Jahrb., Abt. Allg. Zool. Physiol. Tiere 69, 577.

Samassa, P. (1892). Zur Histologie der Ctenophoren. Arch. Mikrosk. Anat. 40, 157243.

Sleigh, M. A. (1968). Metachronal co-ordination of the comb plates of the ctenophore Pleurobrachia. J. Exp. Biol. 48, 111-125.

Verworn, M. (1890). Studien zur Physiologie der Flimmerbewegung. Arch. gesamte Physiol. Menschen Tiere 48, 149-180. 